\title{
PERCEPÇÃO DA POPULAÇÃO SOBRE A ARBORIZAÇÃO DA CIDADE DE SÃO JOÃ̃O DEL-REI, MINAS GERAIS
}

\author{
POPULATION'S PERCEPTION ABOUT THE AFFORESTATION OF SÃO JOÃO DEL- \\ REI, MINAS GERAIS
}

Jaiane da Silva Gonçalves Lourenço ${ }^{1}$

\section{RESUMO}

A arborização nas cidades pode gerar inúmeros benefícios desde ecológicos, como melhoria do microclima e diminuição da temperatura; social, com a melhoria da qualidade de vida dos moradores; e estético, com a existência das árvores para enfeitar a cidade. A percepção ambiental contribui para a relação homem e meio ambiente, com o propósito de servir como base para planos de gestão. $O$ presente trabalho objetivou analisar a percepção dos moradores de São João del-Rei - MG, sobre a arborização urbana. Os dados foram coletados através de entrevistas aos moradores de seis bairros selecionados por apresentarem maior presença de áreas verdes. Os resultados indicam que a maioria dos entrevistados tem ciência que a cidade não é bem arborizada, porém estes não contribuem ou nunca contribuíram para uma melhoria na qualidade das áreas verdes. Apesar dos moradores apontarem desvantagens da arborização, estes reconhecem sua importância sobre o bem-estar da população.

Palavras-chave: Áreas verdes; Moradores; Percepção ambiental; Planejamento; População.

\begin{abstract}
The afforestation in the cities can generate countless benefits from ecological, like improvement of the microclimate and diminution of the temperature; social, with the improvement of the residents' quality of life; and aesthetic, with the existence of trees to decorate the city. The environmental perception contributes to the relationship between man and the environment, with the purpose of serving as a basis for management plans. The present study aimed to analyze the perception of the residents of São João del - Rei - MG, on urban afforestation. Data were collected through interviews with residents of six neighborhoods selected for having a greater presence of green areas. The results indicate that most interviewees are aware that the city is not well-wooded, but these do not contribute or have never contributed to an improvement in the quality of green areas. Although the residents point out disadvantages of afforestation, they recognize its importance on the well-being of the population.
\end{abstract}

Keywords: Green areas; Residents; Environmental perception; Planning; Population

Recebido em 10.01.2017 e aceito em 10.04.2017

1 Bióloga, Msc. Doutoranda do Programa de Pós-Graduação em Botânica Aplicada, UFLA, Lavras/MG. Email: jaianegoncalves@yahoo.com.br 


\section{INTRODUÇÃO}

Entende-se por arborização urbana, toda e qualquer vegetação arbórea que esteja localizada em espaços públicos e privados de uma cidade (OKAMOTO, 2002). As árvores empregadas para compor a arborização urbana apresentam inúmeras vantagens, desde ecológica à social. A importância ecológica compreende a melhoria do microclima associado ao sombreamento, diminuição da temperatura, aumento da umidade relativa do ar e filtragem do ar; proteção do solo através do enraizamento das árvores que asseguram a permeabilidade reduzindo processos erosivos e enchentes; diversidade da flora e fauna, devido às flores e frutos atrativos aos pássaros; redução do nível de ruído (ESCOBEDO; CHACALO, 2008). A importância social se destaca pela melhoria da qualidade de vida da população, pois a vegetação proporciona diferentes cenários de cores, formas e texturas, diminuindo a poluição visual de construções, proporcionando bem estar e redução dos níveis de estresse humano (MOSER et al., 2010).

Quando implantada de maneira inadequada, a arborização pode causar prejuízos e transtornos. Os problemas mais relevantes estão relacionados com plantio inadequado de espécies arbóreas, que podem crescer ao ponto de atingir redes elétricas, postes de iluminação, ou suas raízes se aprofundam e atingem redes de água e esgoto, além das raízes superficiais que podem provocar o levantamento de calçadas (IWAMA, 2014).

Com o aumento da ocupação das cidades, a transfiguração dos espaços urbanos tornou-se crescente, afetando de maneira negativa o meio ambiente e assim a qualidade de vida da população (ZEM; BIONDI, 2014).

Segundo Rio e Oliveira (1999), para que haja melhor compreensão do ambiente urbano, devem ser feitos estudos para analisar a percepção da população em relação às questões ambientais, pois a população sente diretamente os efeitos causados pela qualidade ambiental. A percepção ambiental compreende a relação entre o ser humano e o meio ambiente, na forma de estabelecer perspectivas harmoniosas sobre a forma como a sociedade vê e convive com o ambiente que a envolve (OKAMOTO, 2002).

Estudos sobre a percepção ambiental de moradores a respeito da arborização urbana contribuem para o entendimento da relação entre moradores e o meio ambiente, a fim de ser utilizado como fonte para o planejamento e gestão de áreas verdes (QUADROS; FREI, 2009).

O município de São João del-Rei, Minas Gerais, enfrenta sérios problemas de gestão da arborização urbana. Há poucas árvores e estas estão localizadas, em sua maioria, em avenidas principais da cidade, sendo que muitos bairros possuem ruas sem uma única árvore. Neste contexto, o estudo teve como objetivo avaliar a percepção dos moradores de São João 
del-Rei, Minas Gerais, em relação á arborização urbana, a fim de contribuir para planos de gestão futuros.

\section{MATERIAL E MÉTODOS}

O trabalho foi realizado em São João del-Rei, Minas Gerais, município localizado na

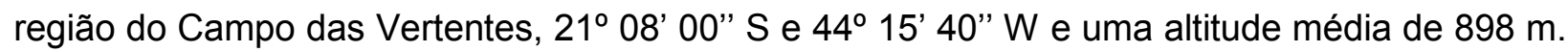
A cidade possui uma área de $1.464,327 \mathrm{~km}^{2}$ e abriga uma população de aproximadamente 89 mil habitantes de acordo com os dados do Instituto Brasileiro de Geografia e Estatística (2010).

O clima é do tipo Cwa, de acordo com a classificação de Köppen, caracterizado por invernos secos e verões chuvosos, com temperatura média anual em torno de $19,2^{\circ} \mathrm{C}$, com mínima de $3^{\circ} \mathrm{C}$ no inverno e máxima de $38^{\circ} \mathrm{C}$ no verão.

A cidade é cortada pelo Córrego do Lenheiro que deságua no Rio das Mortes, afluente do Rio Carandaí, e estes três rios são responsáveis pelas inundações decorrentes em São João del-Rei. As serras de São José (leste) e do Lenheiro (oeste), compõem a paisagem e diversidade da cidade, apresentando a parte superior das serras cobertas por vegetação de campo rupestre, interrompidas por matas de galeria e vegetação de cerrado (SILVA et al., 2011).

A coleta dos dados sobre a percepção dos moradores foi preparada com a aplicação de um questionário estruturado, com perguntas fechadas (Figura 1), para observar a percepção de cada um quanto à arborização dos seis bairros selecionados e da cidade de São João delRei.

Foram realizadas 100 entrevistas com moradores da cidade de São João del-Rei. O número de entrevistados diz respeito aos moradores que concordaram em ceder uma entrevista, pois muitos se recusaram, alegando não entender do assunto.

Os pontos amostrados foram os bairros: Bela Vista, Bonfim, Centro, Dom Bosco, Fábricas e Matosinhos. Optou-se em realizar a pesquisa nesses bairros por apresentarem maior movimentação de moradores, presença de praças ou áreas de lazer, e por se serem áreas que apresentam o maior índice de arborização na cidade.

Após a realização de todas as entrevistas, procedeu-se com a compilação e análise dos dados que foram obtidos e convertidos em gráficos para melhor visualização. 


\section{Data:}

\section{Questionário}

Bairro:

Sexo:

( ) Feminino ( ) Masculino

Grau de escolaridade:

( ) Analfabeto

( ) Ensino fundamental

( ) Ensino médio

( ) Ensino superior

1- Você é natural de São João del-Rei?

( ) $\operatorname{Sim}($ ) Não

2- Quanto tempo reside na cidade?

3- Como classificação a arborização da sua rua?

( ) Pouco arborizada ( ) Razoavelmente arborizada ( ) Muito arborizada

4- Você está satisfeito com a arborização da cidade?

( ) $\operatorname{Sim}($ ) Não

5- Você contribui para a arborização da sua rua?

( ) $\operatorname{Sim}($ ) Não

6- Se colabora, de que forma?

( ) Manutenção das árvores (poda)

( ) Plantando árvores

( ) Preservando

7- Quais as vantagens da arborização urbana em sua opinião?

( ) Estética

( ) Presença de animais

( ) Redução de calor

( ) Sombra

( ) Não possui vantagens

8- Quais as desvantagens da arborização urbana em sua opinião?

( ) Sujeira das ruas

( ) Levantamento de calçadas

( ) Problemas com rede de esgoto, telefonia e de energia

( ) Não possui desvantagens

9- Quem é responsável pela arborização e manutenção das árvores?

( )Prefeitura

( ) Companhias de telefonia, energia

( ) Associação de moradores do bairro

( ) Os próprios moradores

( ) Não sei

10- Você acha que sua rua tem condições de ser arborizada?

( ) Sim ( ) Não

11- Você plantaria uma árvore em sua calçada?

( ) Sim ( ) Não

Figura 1. Questionário aplicado aos moradores de São João del-Rei

Figure 1. Questionnaire applied to residents of São João del Rei 


\section{RESULTADOS E DISCUSSÃO}

Em relação ao perfil dos entrevistados, 65\% são do sexo feminino e 35 \% são do sexo masculino. Destes moradores, $40 \%$ possuem ensino médio, 30\% possuem ensino superior e $27 \%$ frequentaram somente o ensino fundamental. Apenas $3 \%$ dos moradores entrevistados não possuem qualificação escolar.

Quanto ao tempo de residência na cidade, a maior parte dos entrevistados (52\%) vieram de outras cidades, isso se deve ao fato de São João del-Rei ser uma cidade universitária, e 48\% são nascidos e criados em São João del-Rei. Mediante diálogos do entrevistador com os entrevistados, pôde-se notar que os moradores são joanenses conhecem o processo de transformação pelo qual a cidade passou. Parte destes entrevistados afirmou que algumas ruas eram suficientemente arborizadas, mas com o aumento da população foram substituídas por ruas e casas. Enquanto que em outras localidades, principalmente onde havia uma linha de trem, as áreas foram arborizadas, como é o caso da Avenida Leite de Castro, em que o canteiro central, antes uma linha de trem, foi preenchido por árvores.

Quando indagados sobre a arborização atual de suas ruas, $76 \%$ consideraram como pouco arborizadas, $13 \%$ razoavelmente arborizadas e $11 \%$ como muito arborizadas. Resultados semelhantes foram encontrados no estudo de Souza et al. (2013), no município de Alegre - ES. Neste trabalho foram entrevistados moradores de quatro bairros (Centro, Guararema, Nova Alegre e Vila do Sul) e constatou-se que em três bairros a maioria dos moradores classificou suas ruas como pouco arborizadas. Para as ruas ditas como pouco arborizadas, foi justificado a falta de espaço para implantação de espécies arbóreas. Com o aumento da urbanização e por ser uma cidade antiga, São João del-rei não foi planejada com ruas que portassem calçadas com espaço suficiente para o convívio da população e a arborização urbana.

Com relação às avaliações considerando a arborização da cidade de São João delRei, 55\% dos moradores entrevistados não demonstraram satisfação com a arborização da cidade, alegando a necessidade de mais espaços verdes e que a falta de árvores ocasiona um aumento da temperatura, principalmente no verão.

Ao analisar a contribuição da população com a arborização urbana, notou-se que $76 \%$ dos entrevistados não contribuem com a arborização de suas ruas ou da cidade, enquanto que $24 \%$ dos entrevistados afirmaram que contribuem ou contribuíram de alguma forma. Muitos dos entrevistados afirmaram não contribuir por falta de tempo ou até mesmo experiência, por não saberem lidar com as plantas. Diante desta pergunta, muitos moradores não sabiam ao certo se contribuíam ou não. Para eles, essa tarefa é obrigação da prefeitura. 
Dentre as formas de contribuição para a arborização da cidade, 46\% dos moradores que alegaram contribuir com a arborização apontaram que ajudam com o plantio de novas mudas onde não há vegetação ou com o replantio, seguido de $37 \%$ dos moradores que alegaram contribuir preservando as árvores que possuem próximas às suas residências, e 17\% ajudam na manutenção das árvores, com poda, quando esta não é feita pela prefeitura, ou com a limpeza de folhas e flores nas calçadas (Figura 2).

Apesar da boa iniciativa, o plantio deve ser feito de maneira adequada ao espaço onde a árvore será inserida. A incompatibilidade entre a infraestrutura e a arborização pode resultar na inadequação da espécie ou do local do plantio.

Na Vila Estação Colônia, bairro Camobi, Santa Maria - RS, Roppa et al. (2007) constataram que a maioria dos moradores $(64,6 \%)$ contribuem com a arborização da cidade não danificando as árvores, enquanto que 44,6\% colaboram plantando mais árvores e $41,5 \%$ realizam manutenção e poda. Entretanto, o plantio voluntário de novas espécies por parte dos moradores, como foi observado nos resultados, pode causar danos futuros devido à implantação de espécies inadequadas que acarretam no levantamento de calçadas e danos a rede elétrica.

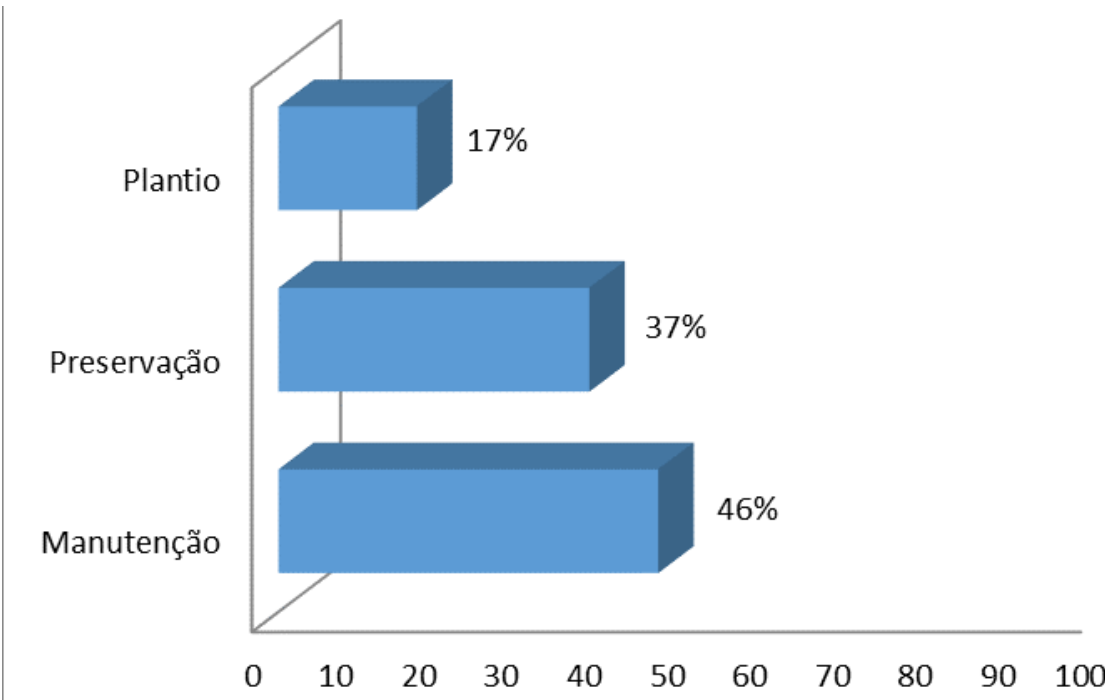

Figura 2. Formas de contribuição para a arborização urbana Figure 2. Forms of contribution to urban afforestation

Quando questionados sobre as vantagens que a arborização urbana pode proporcionar, $61 \%$ dos entrevistados mencionaram a sombra proporcionada pelas árvores, $22 \%$ indicaram redução de calor, ao proporcionar uma sensação de conforto térmico às pessoas, seguido de $9 \%$ dos entrevistados que consideraram a estética, $6 \%$ presença de 
animais e apenas $2 \%$ dos moradores afirmaram não haver vantagens na presença das árvores (Figura 3).

A sensação de frescor diante da sombra produzida pelas árvores é reconhecida pelo moradores. Durantes as estações mais quentes, os entrevistados disseram que nas ruas sem arborização a sensação térmica é mais elevada. Através do sombreamento produzido, as árvores contribuem para a diminuição das altas temperaturas das zonas urbanas, através de um processo denominado evapotranspiração. As plantas utilizam a radiação solar para realizar processos fisiológicos e liberam para a atmosfera vapor de água, que retiram parte do calor e fornecem a sensação de frescor.

Silva et al. (2014) também obtiveram resultados semelhantes em seu trabalho realizado com alunos de duas escolas de Ubá - MG, onde o sombreamento foi a principal vantagem da arborização urbana, representado por $48,8 \%$ dos entrevistados.

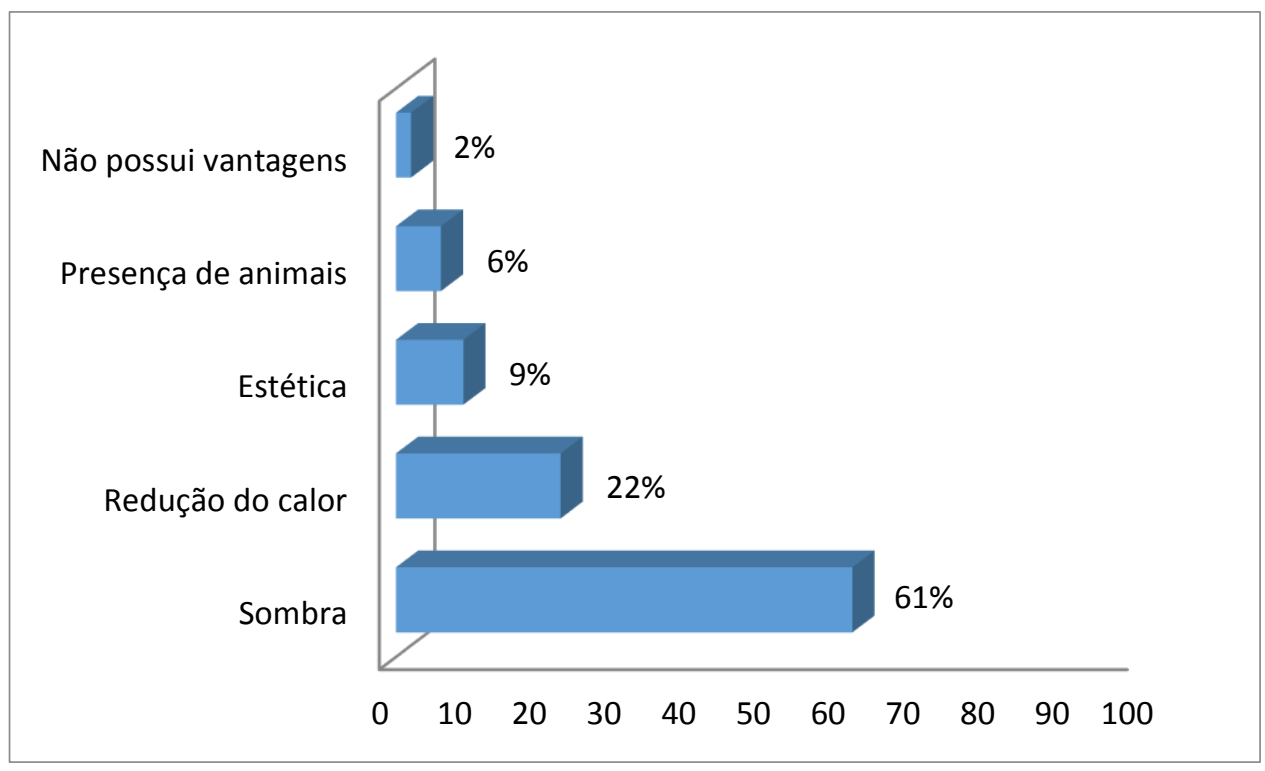

Figura 3. Vantagens da arborização urbana

Figure 3. Advantages of urban afforestation

Em relação às desvantagens decorrentes da arborização urbana em São João del-Rei, a maioria dos entrevistados disseram que as árvores não possuem nenhuma desvantagem, pelo contrário, só trazem benefícios sociais e ambientais. A sujeira nas calçadas foi a opção indicada por $29 \%$ dos entrevistados, seguida de problemas com rede de esgoto e água (16\%) e levantamento de calçadas (9\%) (Figura 4).

Gross et al. (2012) apontaram resultados semelhantes em seu estudo, onde moradores de dois bairros dos três amostrados, classificaram sujeira nas ruas e calçadas como a principal desvantagem da arborização, enquanto que no outro bairro de estudo, problemas com rede elétrica e telefônica se destacou entre os moradores. 
Verdadeiramente pode haver uma incompatibilidade entre as árvores e o meio urbano, mas somente quando resulta da inadequação da espécie ao local de plantio. A inserção errônea de algumas infraestruturas, como aéreas ou subterrâneas, em locais já arborizados agravam a incompatibilidade entre arborização e meio urbano.

O fato de $46 \%$ dos moradores entrevistados não considerarem desvantagens na arborização indica que a população tem consciência da importância da vegetação nos espaços urbanos e dos benefícios que esta pode trazer ou então nunca se encontraram em situações onde a presença de árvores causasse algum transtorno. A caracterização dos problemas da arborização urbana pode estar associada à falta de conscientização ambiental por parte de alguns moradores, aliada à falta de planejamento do poder público em relação ao plantio de espécies adequadas aos diferentes espaços públicos (ROPPA et al., 2007).

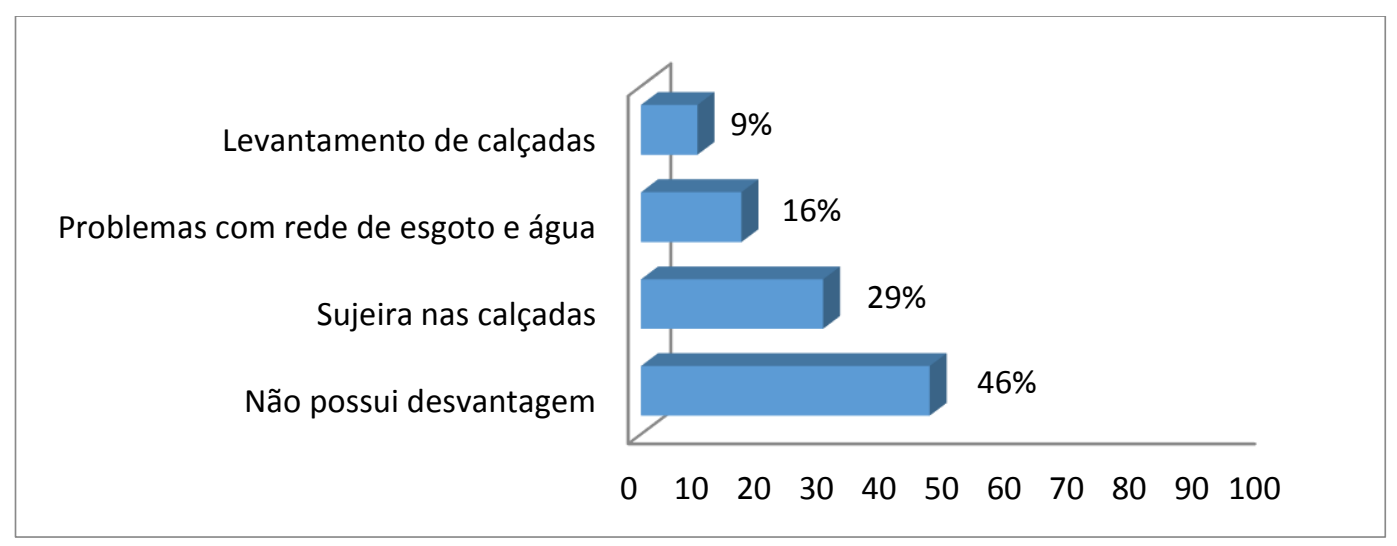

Figura 4. Desvantagens da arborização urbana

Figure 4. Disadvantages of urban afforestation

Quando questionados sobre a responsabilidade dos cuidados das árvores, $47 \%$ das pessoas responsabilizaram a prefeitura, seguida de $23 \%$ dos entrevistados que não souberam responder a quem cabe tal função, $10 \%$ consideraram os moradores, assim como $10 \%$ responderam que era de responsabilidade das associações de moradores dos bairros, e 10\% as empresas de telefonia e energia (Figura 5). Malavasi e Malavasi (2001), em pesquisa no município de Marechal Cândido Rondom - PR, obtiveram resultados semelhantes, onde 73\% dos entrevistaram classificaram a prefeitura como principal responsável pela arborização urbana.

A Lei Orgânica do município de São João del-Rei estabelece algumas responsabilidade da prefeitura acerca da arborização:

Art. 184. Todos têm direito ao meio-ambiente ecologicamente equilibrado, bem este de uso comum do povo e essencial à sadia qualidade de vida, impondo-se ao 
Poder Público Municipal e à coletividade o dever de defendê-lo e preservá-lo para as presentes e futuras gerações, ressalvadas a competência da União e do Estado, na forma da Lei".

Em vista disso, cabe à prefeitura de São João del-Rei a responsabilidade pela arborização urbana.

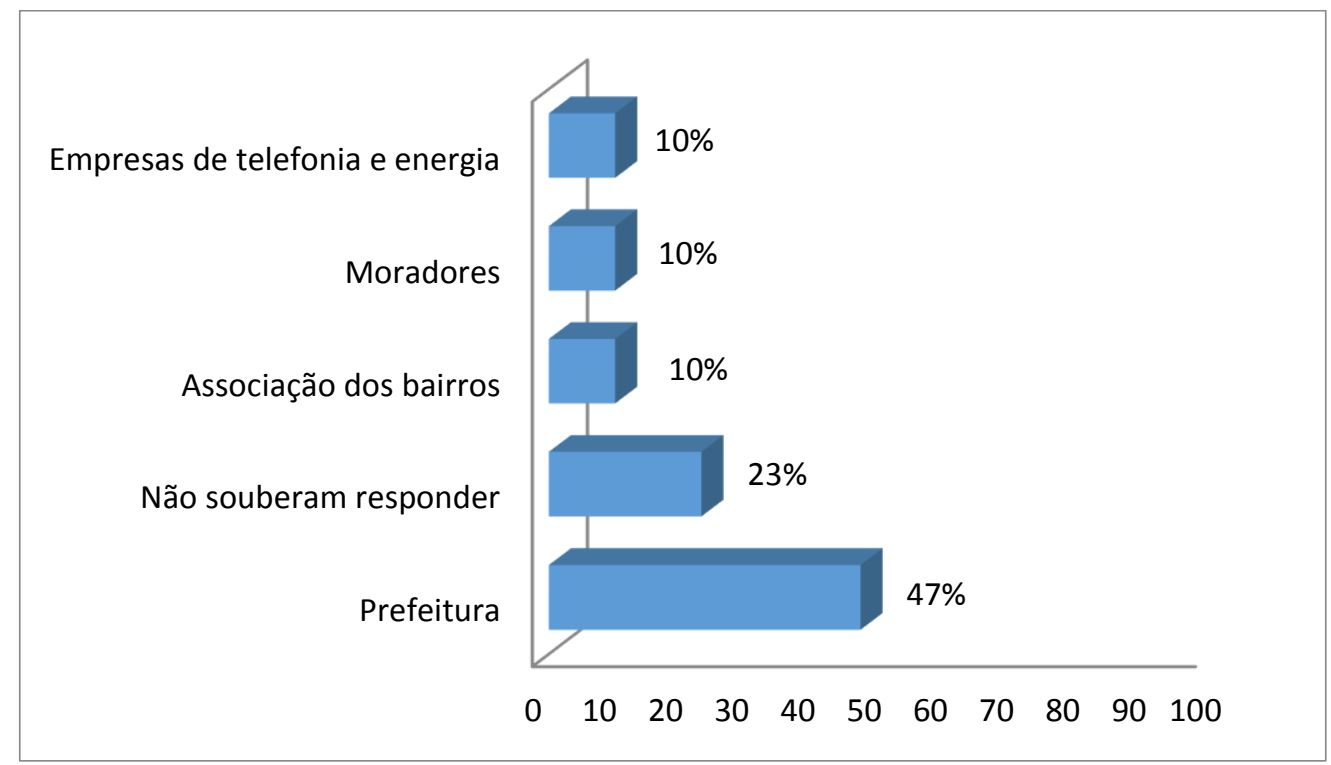

Figura 5. Responsável pela arborização urbana

Figure 5. Responsible for urban afforestation

Foi perguntado aos moradores entrevistados se suas ruas tinham ou não condições de serem arborizadas. Dos entrevistados, 53\% alegaram que não, pois as calçadas eram muito estreitas ou até mesmo não havia calçamento nas ruas, enquanto $47 \%$ consideraram suas ruas adequadas para o plantio de árvores.

Inúmeras ruas de São João del-Rei não possuem árvores e estas não teriam condições de serem implantadas, devido à falta de infraestrutura. Por ser uma cidade histórica, as ruas de pedra ou paralelepípedos não podem ser substituídas por uma via asfaltada, e o plantio das árvores torna-se inviável perante o poder público.

Ao final do questionário os moradores foram perguntados se concordavam em plantar uma árvore na calçada de suas casas, $61 \%$ dos entrevistados concordaram em ter alguma espécie de árvore na calçada de sua residência e 39\% não concordaram, dizendo que não havia espaço suficiente ou que já tiveram algum transtorno com árvores próximas a suas casas. Os moradores se mostraram interessados em contribuir futuramente com a arborização da cidade, mas a falta de conhecimento os limita. 
A arborização urbana deve ser parte integrante dos planos de gestão da prefeitura, para beneficiar o bem-estar e a qualidade de vida da população são joanense.

\section{CONCLUSÕES}

Diante dos resultados obtidos, pode-se concluir que os moradores de São João delRei têm consciência da importância da arborização para o meio ambiente e para o bem-estar da população. Entretanto, a falta de participação da comunidade e do poder público, estão relacionados com a escassez de árvores na cidade de São João del-Rei, MG.

Para que os benefícios da arborização urbana sejam vivenciados, é necessário um planejamento adequado a respeito do plantio das árvores no perímetro urbano, como forma de minimizar os impactos causados por uma arborização inadequada. É necessário a criação de um plano de arborização, juntamente com atividades de educação ambiental, para o replanejamento da arborização já existente e planejamento de arborização para as áreas menos arborizadas.

\section{REFERÊNCIAS}

ESCOBEDO, F.; CHACALO, A. Estimación preliminar de ladescontaminación atmosférica por elarbolado urbano de laciudad de México. Interciencia, Caracas, v.33, n.1, p. 29-33, 2008.

GROSS, A.; DORS, P.; CAMPOS, K. A.; SILVA, A. C.; HIGUCHI, P. Percepção dos moradores e avaliação da arborização em bairros periféricos na cidade de Lages, SC. Revista da Sociedade Brasileira de Arborização Urbana, Piracicaba, v.7, n.2, p.24-36, 2012.

INSTITUTO BRASILEIRO DE GEOGRAFIA E ESTATÍSTICA. Censo 2010. Disponível em: <http://www.ibge.gov.br > Acesso em: 5 de Jul. 2015.

IWAMA, A. Y. Indicador de arborização urbana como apoio ao planejamento de cidades brasileiras. Revista da Sociedade Brasileira de Arborização Urbana, Piracicaba, v.9, n.3, p. 156-172, 2014.

MALAVASI, U. C.; MALAVASI, M. M. Avaliação da arborização urbana pelos residentes estudo de caso em Mal. Cândido Rondon. Ciência Florestal, Santa Maria, v.11, n.1, p. 189193, 2001.

MOSER, P.; SILVA, A. C.; HIGUCHI, P. Arborização urbana: um encontro da natureza com o meio urbano. Espiral, São Paulo, v. 42, n.1, p. 1-10, 2010.

OKAMOTO, J. Percepção ambiental e comportamento: visão holística de percepção ambiental na arquitetura e na comunicação. São Paulo: Mackenzie, 2002. 
QUADROS, L. S.; FREI, F. Percepção ambiental dos residentes da cidade de Assis - SP com relação à arborização viária da Avenida Rui Barbosa. Revista da Sociedade Brasileira de Arborização Urbana, Piracicaba, v.4, n.2, p.16-34, 2009.

RIO, V.; OLIVEIRA, L. (Org). Percepção Ambiental - A experiência brasileira. 2 ed. São Paulo: UFSCAR/Studio Nobel, 1999.

ROPPA, C.; FALKENBERG, J. R.; STANGERLIN, D. M.; BRUN, F. G. K.; BRUN, E. J.; LONGHI, S. J. Diagnóstico da percepção dos moradores sobre a arborização Urbana na Vila Estação Colônia - Bairro Camobi, Santa Maria - RS. Revista da Sociedade Brasileira de Arborização Urbana, Piracicaba, v. 2, n. 2, p.11-30. 2007.

SÃO JOÃO DEL-REI. Lei Orgânica do Município de São João del-Rei, de 21 de maço de 1990.

SILVA, D. R.; TOSTES, R. B.; SILVA, K.; VALENTE, K. Percepção dos alunos das escolas estaduais Raul Soares e Senador Levindo Coelho sobre a arborização urbana no município de Ubá - MG. Revista Educação Ambiental em Ação, Novo Hamburgo, v.49, n.2, p.1-10, 2014.

SILVA, N. G.; ALVES, R. J. V.; PEREIRA, J. F.; RIVADAVIA, F. Lentibulariaceae, Serra de São José, Minas Gerais, Brasil. Check List, Campinas, v. 7, n. 2, p. 120-127, 2011.

SOUZA, S. M.; CARDOSO, A. L.; SILVA, A. G. Estudo da percepção da população sobre a arborização urbana no município de Alegre - ES. Revista da Sociedade Brasileira de Arborização Urbana, Piracicaba, v. 8, n. 2, p.68-85, 2013.

ZEM, L. M; BIONDI, D. Análise da percepção da população em relação ao vandalismo na arborização viária de Curitiba - PR. Revista da Sociedade Brasileira de Arborização Urbana, Piracicaba, v. 9, n. 3, p.86-107, 2014. 